\title{
Watermelon Chlorotic Stunt Virus is Associated with Cucumber Yellow Mosaic Symptoms in Oman
}

\author{
Muhammad Shafiq Shahid", Muhammad Shafiq and Abdullah Muhammad Al-Sadi \\ Department of Plant Sciences, College of Agricultural and Marine Sciences, Sultan Qaboos University, Al-Khod 123, Oman \\ *For correspondence: mshahid@squ.edu.om \\ Received 20 November 2020; Accepted 15 December 2020; Published 25 March 2021
}

\begin{abstract}
Cucumber (Cucumis sativus; family Cucurbitaceae) plants exhibiting begomovirus-like symptoms such as yellowing, mosaics and stunting were studied using cloning, sequencing, Species Demarcation Tool followed by phylogenetic clustering. The complete genome of DNA-A showed maximum sequence identity of $98.7 \%$ with the corresponding DNA-A of an isolate from "Iran" strain of Watermelon chlorotic stunt virus (WmCSV). The DNA-B displayed 97.5\% nt identity with the component of DNA-B of WmCSV from Iran, too. Our results confirmed that yellowing and mosaic symptoms of cucumber are associated with a bipartite begomovirus (WmCSV). This study is the first characterization of WmCSV in association with described symptoms in cucumber from Oman. (C) 2021 Friends Science Publishers
\end{abstract}

Keywords: Geminiviridae; Begomovirus; Cucumis sativus; Watermelon chlorotic stunt virus

\section{Introduction}

Begomoviruses (family Geminiviridae) are circular singlestranded nucleic acids (ssDNA) viruses that are transmitted exclusively by whiteflies and cause severe viral diseases in several economic crops worldwide (Fauquet et al. 2008). In recent classification ssDNA viruses are divided in nine genera (Becurtovirus, Begomovirus, Curtovirus, Eragrovirus, Mastrevirus, Topocuvirus, Turncurtovirus, Capulavirus, and Grablovirus), depending on the genome structure, vectors, and susceptible host (Varsani et al. 2014). Begomoviruses are economically the most damaging among Geminiviradae family and are spread by a complex of whiteflies (Bemisia tabaci Genn.) (Navas-Castillo et al. 2011). Moreover, begomoviruses are distributed into two subgroups; monopartite begomoviruses (comprise of DNAA) or bipartite begomoviruses comprises of two DNA components (DNA-A and DNA-B) about equal size ( 2,800 bp). Both components share approximately 200 nucleotide (nt) DNA sequence with each other which share 80-100\% identity known as the common region. The DNAA encodes proteins essential for virus replication, influence of gene function and vector spreading, whereas the DNA-B molecule is responsible to provide genes which encodes proteins for virus movement and appearance of symptoms in plants (Rojas et al. 2005).

Since first detection and characterization of WmCSV in Iran and Sudan (Kheyr-Pour et al. 2000), it has been spreading into different plant species and transmitting to into diverse geographical areas (Domínguez-Durán et al.
2018). This study indicates the first confirmation of yellow mosaic symptoms of cucumber is associated with a bipartite begomovirus WmCSV in Oman.

\section{Materials and Methods}

\section{Survey and sample collection}

Survey was conducted (December 2016 and 2018) in cucumber fields in the Al-Batinah North (coordinates $23^{\circ} 41^{\prime}$ $26.69^{\prime \prime} \mathrm{N} \mathrm{57^{ \circ }} 53^{\prime} 30.78^{\prime \prime} \mathrm{E}$ ) region of Oman. Approximately $30-40 \%$ of cucumber plants exhibited symptoms like begomovirus infection such as yellowing, mosaics and stunting (Fig. 1). Cucumber plants were infested by medium to high ( 5-10/leaf) whitefly (Bemisia tabaci; Middle EastAsia Minor I, MEAMI) populations. Sixteen different leaf samples were collected (ten symptomatic and six asymptomatic) and were tested for begomovirus infection.

\section{Genomic DNA extraction and initial virus detection}

Plant genomic DNA was extracted from all leaf samples $(n=16)$ followed by CTAB-protocols (Porebski et al. 1997), and the resulting DNA was used in a PCR assay targeting the conserved region ( $550 \mathrm{nt}$ of the core coat protein gene) using universal detection primes AC1048/AV494 (Brown et al. 2001).

\section{Rolling circle amplification and cloning}

To further characterize the virus from cucumber samples, 
four random selected PCR positive samples were used in Rolling Circle Amplification (RCA) as described earlier (Shahid et al. 2017). The concatamers of the RCA products were used in endonuclease reaction and monomer begomovirus fragments $(\sim 2.7 \mathrm{~kb})$ were produced with HindIII and PstI restriction enzymes (Shahid et al. 2019b). The linear DNA fragments were excised from $1 \%$ gel electrophoresis, purified and ligated into pUC19 vector at the compatible restriction enzyme sites.

\section{Sequencing and sequence analysis}

The putative complete components were confirmed and sequenced entirely by Macrogen, Korea. These full-length sequences were compared with related begomovirus sequences using BLASTn analysis at (https://www.ncbi.nlm.nih.gov/). Open Reading Frames (ORFs) in all genomes were discovered using ORF finder (https://www.ncbi.nlm.nih.gov/orffinder/). Nucleotide sequence identity was determined by Species Demarcation Tool (SDT) with MUSCLE algorithm and phylogenetic analysis and tree construction was done in MEGA7 (Kumar et al. 2016). Recombination Detection Program (RDP 4.1) was run as described earlier (Martin et al. 2015).

\section{Results}

\section{Detection of begomovirus}

PCR results confirmed the amplification of amplicon with an expected size $(\sim 550 \mathrm{nt})$ of the conserved coat protein (CP) gene, from all symptomatic cucumber leaf samples, whereas all asymptomatic leaf samples were uniformly negative. The initial sequence analysis of the PCR product confirmed WmCSV (a bipartite begomovirus) is associated with yellowing and mosaic symptoms in cucumber plants. None of the samples were positive for alphasatellite, betasatellite or other begomovirus using universal amplification primers (Bull et al. 2003; Shahid et al. 2019a) either in PCR or by RCA.

\section{Characterization of DNA-A of bipartite begomoviruses}

Full-length monomer molecules of DNA-A were produced with HindIII restriction of RCA product. After sequencing all the sequences contigs were assembled and full-length genome sequences were produced. The resultant full-length assembled sequences shared $99.1-100 \%$ nucleotide (nt) identity with each other and out of those two complete nt sequences were deposited to GenBank (acc no. MK649818 and MK649819). Each sequence was 2,752 nt long and displayed the composition of genes attributes typical to the DNA-A component of Old World (OW) of bipartite begomoviruses. Consisting of four ORFs [Replication associated protein (Rep), Trans-replication associated protein (TrAp), Replication enhancer protein (REn), and

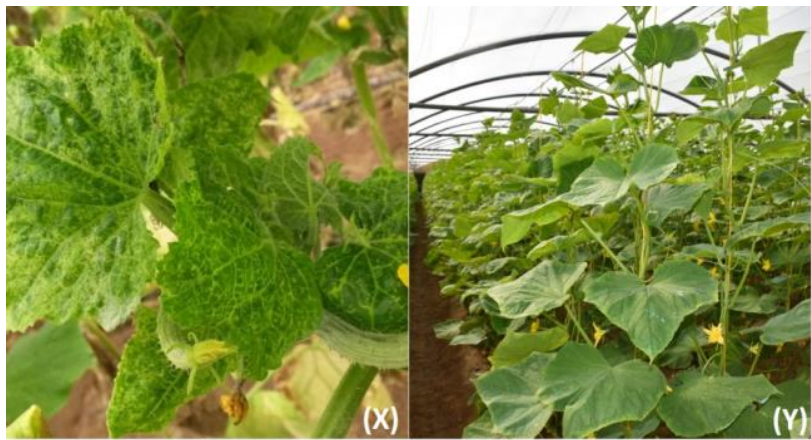

Fig. 1: Cucumis sativus plants showing yellow mosaic symptoms associated with WmCSV $(\mathbf{X})$ in comparison with healthy $C$. sativus plant $(\mathbf{Y})$

AC4 protein] in the complementary-sense strand. Whereas two ORFs were found [Coat protein (AV1) and AV2 protein] in the virion-sense strand (Table 1). Sequence Demarcation Tool (SDT) using pairwise sequence alignments analysis (Muhire et al. 2014) revealed highest nt identity (98.3\%) with the sequences of DNA-A of an isolate of the "Iran" strain of WmCSV (AJ245652) earlier identified in Iran (Kheyr-Pour et al. 2000). A phylogenetic tree further confirms that the WmCSV isolates cluster with WmCSV isolates reported from Iran and Saudi Arabia (Fig. 2A). No evidence of recombination events among bipartite begomovirus complex was found using different algorithms in RDP 4.1 program (Martin et al. 2015).

\section{Characterization of DNA-B of bipartite begomoviruses}

Four full-length cognate sequences of DNA-B components were obtained with PstI restriction of RCA product which shared $99-100 \%$ nt identity with each other and two representative sequences were submitted to GenBank (accession numbers MK649820 and MK649821). Both the DNA-B components displayed genome organizations typical to the DNA-B of earlier discovered bipartite begomovirus, containing the two ORFs; MP: movement protein and NSP: Nuclear shuttle protein in the complementary and virionsense strand respectively (Table 1). Each component was $2,728 \mathrm{nt}$ in length and exhibited $97.3 \%$ nt identity with the DNA-B segment of WmCSV (AJ245653) from Iran (KheyrPour et al. 2000). In phylogenetic analysis the DNA-B of WmCSV isolates cluster with the cognate DNA-B of WmCSV isolates (Fig. 2B).

\section{Discussion}

Mainly bipartite begomoviruses are originated from the New World (central and South America) with the exception of merely a slight number that occurs in the OW (Australia, Japan, China, Indian subcontinent, Africa, Mediterranean and European region) (Zerbini et al. 2017). After the first detection of WmCSV in Iran (Middle East) and Sudan 
Table 1: Features of WmCSV isolated from natural infection of cucumber plants in Oman

\begin{tabular}{|c|c|c|c|c|c|c|c|c|c|c|c|c|c|}
\hline \multirow[t]{3}{*}{ Isolate } & \multicolumn{8}{|c|}{ Watermelon chlorotic stunt virus (DNA-A) } & \multirow{2}{*}{\multicolumn{5}{|c|}{ DNA-B }} \\
\hline & \multirow{2}{*}{ Accession\# } & \multirow{2}{*}{$\begin{array}{l}\text { Size } \\
\text { (nt) }\end{array}$} & \multicolumn{6}{|c|}{ Position of genes (coordinates)/no. of amino acids [predicted coding capacity in kDa] } & & & & & \\
\hline & & & $\overline{\mathrm{CP}}$ & V2 & Rep & TrAP & REn & $\mathrm{C} 4$ & Clone & Accession\# & $\begin{array}{l}\text { Size } \\
\text { (nt) }\end{array}$ & $\begin{array}{l}\text { Position of BV1 } \\
\text { gene(coordinates)/ } \\
\text { no. of amino acids } \\
\text { [predicted coding } \\
\text { capacity in kDa] }\end{array}$ & $\begin{array}{l}\text { Position of } \mathrm{BC} 1 \\
\text { gene(coordinates)/ } \\
\text { no. of amino acids } \\
\text { [predicted coding } \\
\text { capacity in } \mathrm{kDa} \text { ] }\end{array}$ \\
\hline \multirow[t]{2}{*}{$18 \mathrm{P}$} & MK649818 & 2,752 & $315-1091$ & $155-514$ & $1540-2625$ & $1233-1640$ & $1088-1492$ & $2328-2471$ & & \multirow[t]{2}{*}{2 MK649820 } & 2,728 & $500-1255$ & $1295-2215$ \\
\hline & & & $257(28.7)$ & $119(13.9)$ & $361(41.30)$ & 135 (15.7) & $134(15.7)$ & $47(5.6)$ & & & & $251(27.9)$ & 306 (34.04) \\
\hline \multirow[t]{2}{*}{$20 \mathrm{P}$} & MK649819 & 2,752 & $315-1091$ & $155-505$ & $1540-2625$ & $1233-1640$ & $1088-1492$ & $2328-2471$ & & \multirow{2}{*}{ MK649821 } & 2,728 & $500-1255$ & $1295-2215$ \\
\hline & & & $257(28.7)$ & $116(13.1)$ & $361(41.30)$ & 135 (15.7) & $134(15.7)$ & $47(5.6)$ & & & & $251(27.9)$ & $306(34.04)$ \\
\hline
\end{tabular}
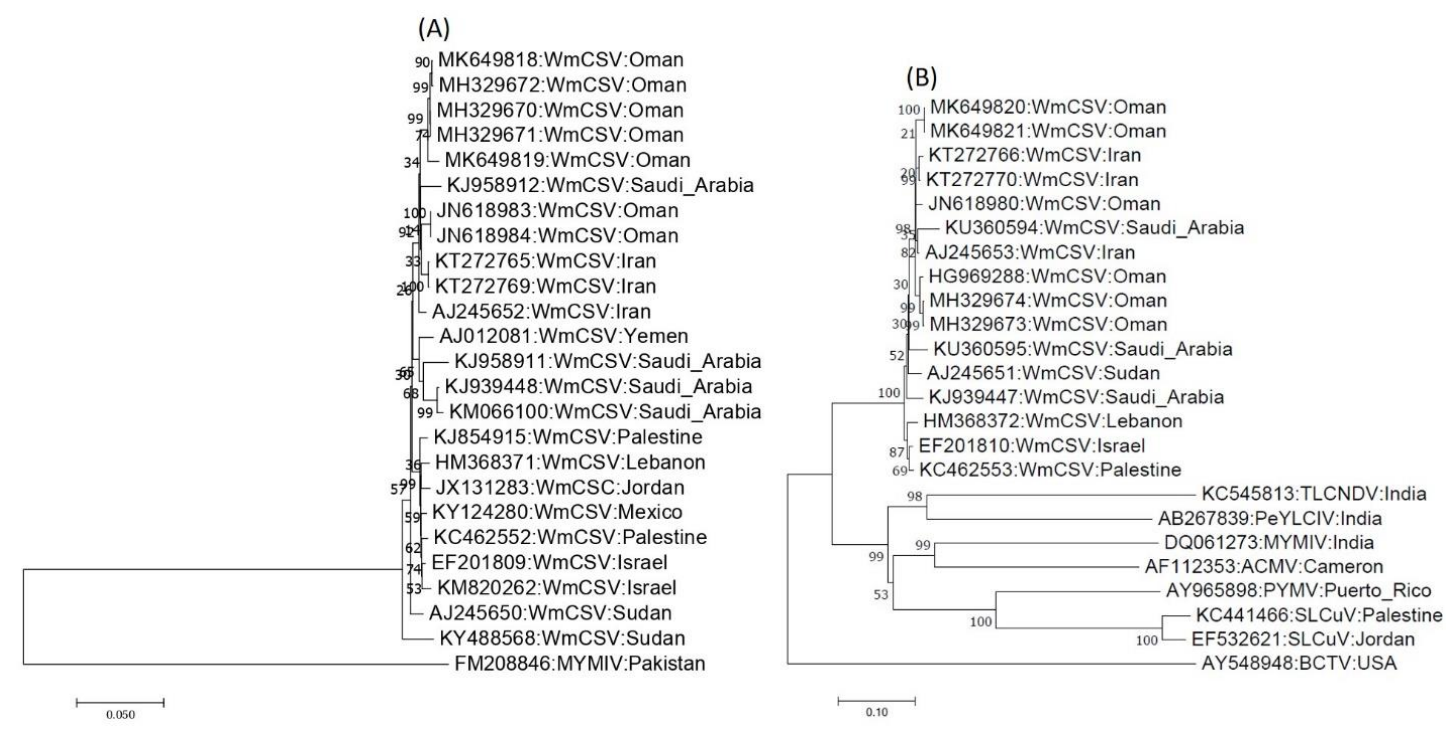

Fig. 2: Phylogenetic dendrograms was constructed in MEGA7 using selected sequences of DNA-A (A) and DNA-B (B) of WmCSV components (Kumar et al., 2016) with 1000 bootstrap values at the nodes, where vertical and horizontal branches are arbitrary and proportional respectively (Felsenstein 1985). The trees were rooted on the sequence of MYMIV-FM208846 and BCTV-AY548948, respectively. The GenBank acc. no and country of origins for each DNA are indicated in each case

(North Africa) (Kheyr-Pour et al. 2000), it has been increasing its host range and transmitting to diverse hosts and geographical areas. For instance, in the past $\mathrm{WmCSV}$ has been reported to infect watermelon, cucurbits, squash, pumpkin in Jordan, Lebanon and Oman respectively (AlMusa et al. 2011; Khan et al. 2012; Samsatly et al. 2012; Shafiq et al. 2020). More recently, WmCSV has been reported in South America i.e., Mexico (Domínguez-Durán et al. 2018). Cucumber is an extensively grown as a greenhouse vegetable crop in Oman as well as in other countries. However, recently it has been reported as the host for different viruses like squash leaf curl virus (SLCV), mungbean yellow mosaic virus (MYMIV) in Palestinian and Oman (Ali-Shtayeh et al. 2010; Shahid et al. 2018). AlBatinah region is the main agriculture-cropping area where several diverse crops are grown in the winter season in Oman. Thus, there is possibility that whitefly vector; containing the WmCSV particles can transmit them to other crops. Further genetic diversity including different plant species needs to be investigated to determine geographical distribution of this bipartite begomovirus in the country.
Different options are available to control these begomoviruses, for instance by targeting different coding genes (Replication protein and/or Coat protein etc.) and intergenic regions of cotton leaf curl virus (CLCuV) and tomato yellow leaf curl virus (TYLCV), respectively (Ji et al. 2015; Khan et al. 2019). However, CRISPR-Cas9 proved to be more efficient tool in Nicotiana benthamiana genome editing (Mubarik et al. 2016, 2019), which can be used to develop resistance in different plant species in near future.

\section{Conclusion}

This is the first evidence of WmCSV infecting cucumber in Oman. The findings of another host infected with WmCSV demonstrate increasing host range of this virus in Arabian Peninsula.

\section{Acknowledgments}

This study was funded by Sultan Qaboos University (IG/AGR/CROP/20/02). 


\section{Author Contributions}

MSS design, perform experiment and wrote the manuscript. MS prepared of samples for sequencing and AMA edited the manuscript.

\section{Conflict of Interest}

The authors of this article have no conflict of interest

\section{Data Availability Declaration}

The authors declare that data reported in this article are available with the corresponding author and will be provided on reasonable demand

\section{Ethics Approval}

Not applicable

\section{References}

Ali-Shtayeh MS, RM Jamous, EY Husein, MY Alkhader (2010). First report of squash leaf curl virus in squash (Cucurbita pepo), melon (Cucumis melo), and cucumber (Cucumis sativa) in the northern West Bank of the Palestinian Authority. Plant Dis 5:640-640

Al-Musa A, G Anfoka, A Al-Abdulat, S Misbeh, FH Ahmed, I Otri (2011). Watermelon chlorotic stunt virus (WmCSV): A serious disease threatening watermelon production in Jordan. Virus Genes 43:79-89

Brown JK, AM Idris, I Torres-Jerez, GK Banks, SD Wyatt (2001). The core region of the coat protein gene is highly useful for establishing the provisional identification and classification of begomoviruses. Arch Virol 146:1581-1598

Bull SE, RW Briddon, PG Markham (2003). Universal primers for the PCRmediated amplification of DNA 1: A satellite-like molecule associated with begomovirus-DNA $\beta$ complexes. Mol Biotechnol 23:83-86

Domínguez-Durán G, EA Rodríguez-Negrete, JJ Morales-Aguilar, E Camacho-Beltrán, JL Romero-Romero, MA Rivera-Acosta, NE Leyva-López, A Arroyo-Becerra, J Méndez-Lozano (2018). Molecular and biological characterization of Watermelon chlorotic stunt virus (WmCSV): An Eastern Hemisphere begomovirus introduced in the Western Hemisphere. Crop Prot 103:51-55

Fauquet CM, RW Briddon, JK Brown, E Moriones, J Stanley, M Zerbini, X Zhou (2008). Geminivirus strain demarcation and nomenclature. Arch Virol 153:783-821

Felsenstein, J (1985). Confidence limits on phylogenies: An approach using the bootstrap. Evolution, 39: 783-791

Ji X, H Zhang, Y Zhang, Y Wang, C Gao (2015). Establishing a CRISPRCas-like immune system conferring DNA virus resistance in plants. Nat Plants 1; Article 15144

Khan AJ, S Akhtar, RW Briddon, U Ammara, AM Al-Matrushi, S Mansoor (2012). Complete nucleotide sequence of Watermelon chlorotic stunt virus originating from Oman. Viruses 4:1169-1181
Khan Z, SH Khan, A Ahmad, S Aslam, MS Mubarik, S Khan (2019). CRISPR/dCas9-mediated inhibition of replication of begomoviruses. Intl J Agric Biol 21:711-718

Kheyr-Pour A, K Bananej, G Dafalla, P Cacigali, E Noirs, A Ahoonmanesh, H Lecoq, B Gronenborn (2000). Watermelon chlorotic stunt virus from the Sudan and Iran: Sequence comparisons and identification of a whitely-transmission determinant. Phytopathology 90:629-635

Kumar S, G Stecher, K Tamura (2016). MEGA7: Molecular evolutionary genetics analysis version 7.0 for bigger datasets. Mol Biol Evol 33:1870-1874

Martin DP, B Murrell, M Golden, A Khoosal, B Muhire (2015). RDP4: Detection and analysis of recombination patterns in virus genomes. Virus Evol 1; Article vev003

Mubarik MS, SH Khan, B Sadia, A Ahmad (2019). CRISPR-Cas9 based Suppression of cotton leaf curl virus in Nicotiana benthamina. Intl $J$ Agric Biol 22:517-522

Mubarik MS, SH Khan, A Ahmad, Z Khan, M Sajjad, IA Khan (2016). Disruption of phytoene desaturase gene using transient expression of Cas9: gRNA Complex. Intl J Agric Biol 18:990-996

Muhire BM, A Varsani, DP Martin (2014). SDT: A virus classification tool based on pairwise sequence alignment and identity calculation. PLOS One 9; Article e108277

Navas-Castillo J, E Fiallo-Olivé, S Sánchez-Campos (2011). Emerging virus diseases transmitted by whiteflies. Annu Rev Phytopathol 49:219-248

Porebski S, LG Bailey, BR Baum (1997). Modification of a CTAB DNA extraction protocol for plants containing high polysaccharide and polyphenol components. Plant Mol Biol Rep 1:8-15

Rojas MR, C Hagen, WJ Lucas, RL Gilbertson (2005). Exploiting chinks in the plant's armor: evolution and emergence of geminiviruses. Аnnu Rev Phytopathol 43:361-394

Samsatly J, H Sobh, M Jawhari, C Najjar, A Haidar, Y Abou-Jawdah (2012). First report of Watermelon chlorotic stunt virus in cucurbits in Lebanon. Plant Dis 96; Article 1703

Shafiq M, MN Sattar, MS Shahid, AM Al-Sadi, RW Briddon (2020). Interaction of watermelon chlorotic stunt virus with satellites. Aust Plant Pathol 3:1-2

Shahid MS, M Shafiq, A Raza, AM Al-Sadi, RW Briddon (2019a) Molecular and biological characterization of Chilli leaf curl virus and associated Tomato leaf curl betasatellite infecting tobacco in Oman. Virol J 16; Article 131

Shahid MS, M Shafiq, M Ilyas, A Raza, MN Al-Sadrani, AM Al-Sadi, RW Briddon (2019b). Frequent occurrence of mungbean yellow mosaic India virus in tomato leaf curl disease affected tomato in Oman. Sci Rep 12; Article 16634

Shahid MS, IH Al-Mahmooli, AM Al-Sadi, RW Briddon (2018). Identification of Mungbean yellow mosaic India virus infecting cucumber in Oman. Plant Dis 102; Article 465

Shahid MS, RW Briddon, AM Al-Sadi (2017). Identification of Mungbean yellow mosaic Indian virus associated with tomato leaf curl betasatellite infecting Phaseolus vulgaris in Oman. J Phytopathol 165:204-211

Varsani A, J Navas-Castillo, E Moriones, C Hernández-Zepeda, A Idris, JK Brown, FM Zerbini, DP Martin (2014). Establishment of three new genera in the family Geminiviridae: Becurtovirus, Eragrovirus and Turncurtovirus. Arch Virol 159:2193-2203

Zerbini FM, RW Briddon, A Idris, DP Martin, E Moriones, J NavasCastillo, R Rivera-Bustamante, A Varsani, IR Consortium (2017). ICTV virus taxonomy profile: Geminiviridae. $J$ Gen Virol 98:131-133 